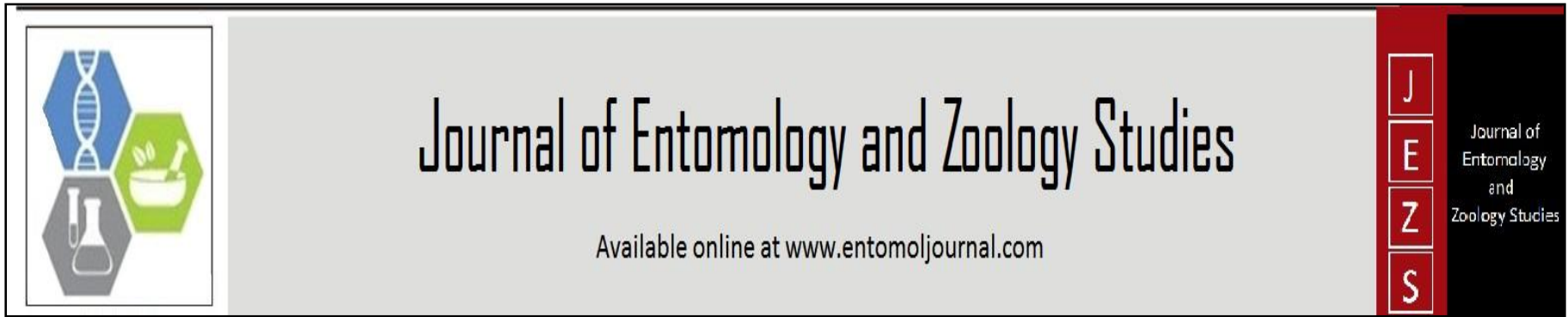

E-ISSN: 2320-7078 P-ISSN: 2349-6800 JEZS 2017; 5(2): 1558-1560 (C) 2017 JEZS

Received: 24-01-2017

Accepted: 25-02-2017

Mark Ian Cooper Department of Biological Sciences, University of Cape Town, Private Bag X3, Rhodes Gift, Rondebosch 7701, South Africa.

\section{Correspondence}

Mark Ian Cooper

Department of Biological

Sciences, University of Cape

Town, Private Bag X3, Rhodes

Gift, Rondebosch 7701, South

Africa.

\title{
Relative sexual size dimorphism in Centrobolus digrammus (Pocock) compared to 18 congenerics
}

\section{Mark Ian Cooper}

\section{Abstract}

The present research was aimed to study relative sexual size dimorphism of Centrobolus digrammus (Pocock) compared to 18 congenerics. Millipedes illustrate reversed sexual size dimorphism (SSD) as females are larger than males; and corroborate Rensch's rule as this dimorphism increases with body size. SSD was calculated in 18 species of the genus Centrobolus and illustrated as a regression. The approximate relative position of $C$. digrammus was shown from measurements taken at Simon's Town Waterfall, South Africa (March 1997). The size of $C$. digrammus was 49.9 X $4 \mathrm{~mm}$ : 54.5 X $4.8 \mathrm{~mm}$ (males: females; $\mathrm{n}=6$ ) and logged (females/ $\mathrm{x}=2.993$; males/y $=2.790$ ). The mean volume ratio for $C$. digrammus was 1.599. The evidence suggests the proximate cause for SSD in $C$. ruber is sexual bimaturism while the ultimate cause in Centrobolus is intersexual competition.

Keywords: Centrobolus, digrammus, dimorphism, millipede, SSD, size

\section{Introduction}

Sexual size dimorphism is prevalent in arthropods and females are usually larger than males $e$. $g$. beetles ${ }^{[1]}$, sea spiders ${ }^{[2]}$, orthopterans ${ }^{[15]}$. Behavioural patterns such as provisioning versus non- provisioning relate to SSD ${ }^{[3]}$. Millipedes illustrate reversed sexual size dimorphism (SSD) and females are larger than males ${ }^{[4-9]}$. SSD in forest millipedes has successfully been understood as volumetric measurements using Centrobolus to corrobrate Rensch's rule ${ }^{[4-7]}$. Based on the assumption of equal developmental rates in males and females, the proximate cause for Rensch's rule is sexual bimaturism ${ }^{[10-11]}$. The general trend of SSD has been calculated for Centrobolus and bimaturism shown [7, 11]. The present study was aimed to illustrate the trend of SSD for the genus Centrobolus and pinpoint the position of $C$. digrammus relative to 18 congenerics in order to determine whether males and/or females follow the trend of Rensch's rule.

\section{Materials and Methods}

Three factors were measured from 19 Centrobolus species: (1) body length (mm) by placing individuals collected in South Africa (1996-1998) alongside a plastic rule (calibrated in mm); (2) width (mm) with Vernier calipers; and (3) mass (accurate to $0.01 \mathrm{~g}$ ) was measured with a Mettler balance. C. digrammus (Pocock) were collected at Simon's Town Waterfall, South

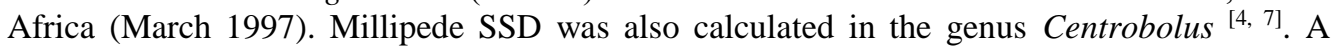
regression of male volume on female volume was used to show the position of 18 species and the size of $C$. digrammus was taken as a volumetric measurement and inserted into a Microsoft (MS) Excel spreadsheet and converted using the logorithmic (mathematical) equation. The chart for SSD in 18 species was captured, copied and exported using the snapshot function in the programme Soda Portable Document File (PDF) 8. It was pasted into a MS Word file and the position of $C$. digrammus pinpointed.

\subsection{Statistical Analysis}

The basic descriptive figures were statistically compared using Statistica. Body length: width ratios were compared on arcsine transformed data. The mean values of length, width and number of segments was extracted from published data for 18 species intersexual comparisons performed using Wilcoxon matched pairs tests. Size was perceived as body volume and

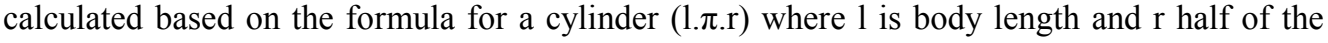
width. SSD was estimated as the mean female volume divided by mean male volume and converted into a SSD index by subtracting 1. Allometry for SSD was based on a general allometric model where male size $=\alpha(\text { female })^{\beta}$. 


\section{Results}

The quantitative resolution of Rensch's rule for 18 species of Centrobolus together with the relative estimated position of C. digrammus is shown in Fig. 1. The size of $C$. digrammus was 49.9 X 4 mm: 54.5 X 4.8 mm (males: females; $n=6$ ) and logged (females $/ \mathrm{x}=2.790 ;$ males/y $=2.993$ ) and plotted (Fig. 1). The mean volume ratio (female volume/male volume) for C. digrammus was 1.599. SSD was visible with the naked eye (Fig. 2).

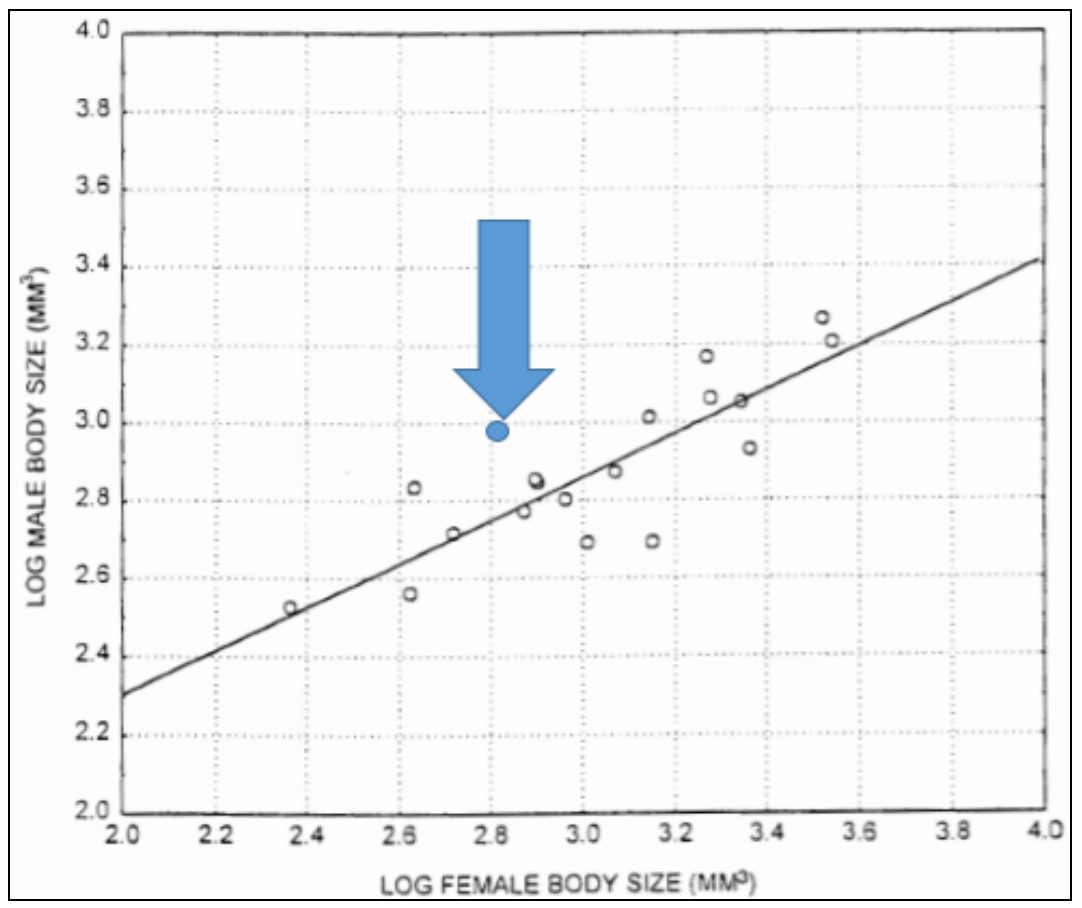

Fig 1: Quantitative resolution of Rensch's rule for 18 species of spirobolidan millipedes of the genus Centrobolus. Isometry for sexual size

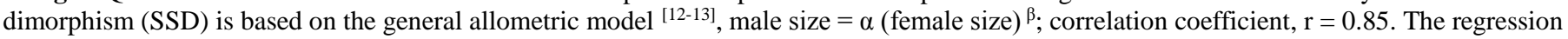
of $\log$ (female size) on $\log$ (male size) would generate an identical relationship with $\beta<1$. The estimated position of $C$. digrammus is shown by the arrow and filled circle.
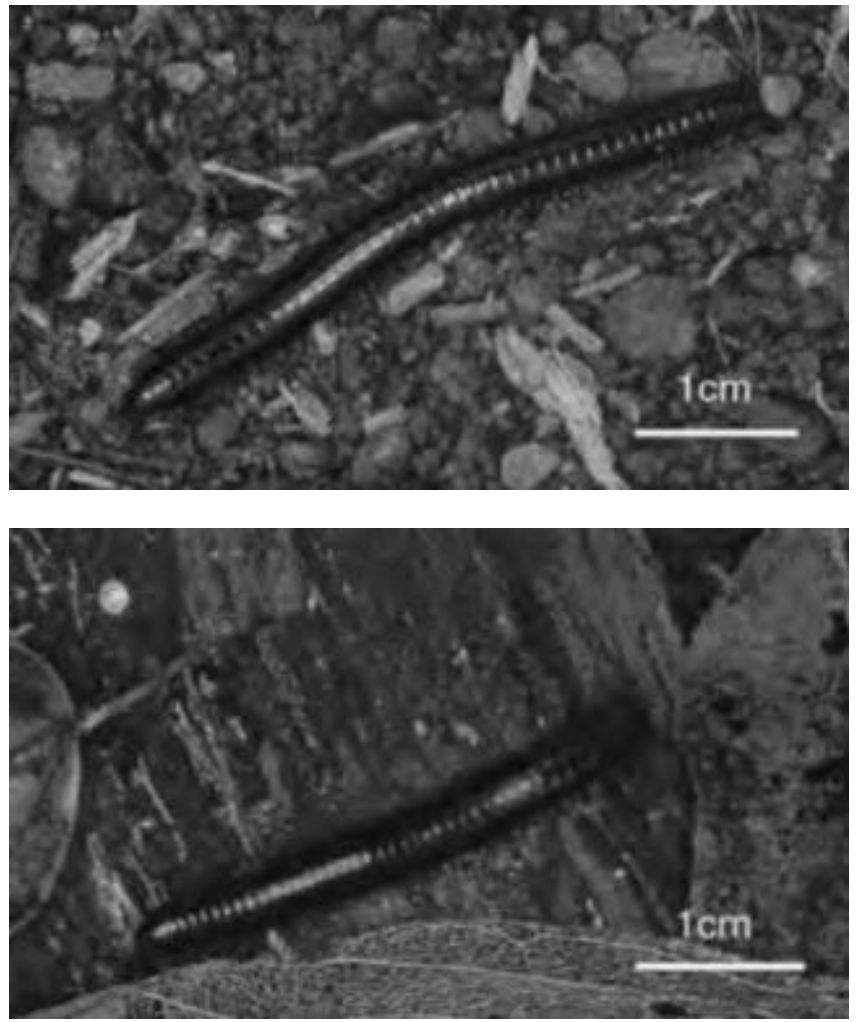

Fig 2: SSD in Centrobolus digrammus (male above; female below).

\section{Discussion}

Unlike previous studies on SSD in invertebrates these results consistently corroborated Rensch's rule ${ }^{[18]}$. Figure 1 shows the finding for Centrobolus where mean volume ratios ranged from 0.63-2.72 with the regression of log male volume on $\log$ female volume was highly significant with a positive slope less than 1; showing females get larger than males with an increase in body size ${ }^{[4,7,9]}$. The mean volume ratio of 1.599 was at the middle region of the trend for the genus. $C$. digrammus SSD was unlike $C$. fulgidus and $C$. inscriptus with ordinarily small males and larger females which are similar compared to the other 18 Centrobolus species for which data is available. Importantly, because the position of $C$. fulgidus was above the line corroborating Rensch's rule it suggested females were larger than males or males were smaller than females relative to other members of the genus. As a proximate cause for SSD in millipedes the evidence corroborated the sexual bimaturism hypothesis ${ }^{[11]}$. As an ultimate cause for SSD this together with ecological evidence corroborated the intersexual competition hypothesis [14-16]. The small-male mating advantage may apply in this species [17].

\section{Conclusion}

C. digrammus was unlike $C$. inscriptus with ordinarily small males and larger females which are similar compared to the other 18 Centrobolus species for which data is available.

\section{Acknowledgement}

Gary Cooper provided the computer for the write-up of the publication.

\section{References}

1. Rudoy A, Ribera I. Evolution of sexual dimorphism and Rensch's rule in the beetle genus Limnebius (Hydraenidae): is sexual selection opportunistic? PeerJ. 
2017; 5:e3060; DOI 10.7717/peerj.3060.

2. Barreto FS, Avise JC. Polygynandry and sexual size dimorphism in the sea spider Ammothea hilgendorfi (Pycnogonida: Ammotheidae), a marine arthropod with brood-carrying males. Molecular Ecology. 2008; 17(18):4164-4175.

3. Shreeves G, Field J. Parental care and sexual size dimorphism in wasps and bees. Behavioural Ecology and Sociobiology. 2008; 62:843-852.

4. Cooper MI. Sexual size dimorphism and corroboration of Rensch's rule in Chersastus millipedes (Diplopoda: Trigoniulidae). Journal of Entomology and Zoology Studies. 2014; 2(6):264-266.

5. Cooper MI. Heavier-shorter-wider females in the millipede Centrobolus inscriptus (Spirobolida: Trigoniulidae). Journal of Entomology and Zoology Studies. 2016; 4(2):509-510.

6. Ilić BS, Mitić BM, Makarov SE. Sexual dimorphism in Apfelbeckia insculpta (L. Koch, 1867) (Myriapoda: Diplopoda: Callipodida). Archives of Biological Sciences. 2016; 68:1-20.

7. Cooper MI. The relative sexual size dimorphism of Centrobolus inscriptus compared to 18 congenerics. Journal of Entomology and Zoology Studies. 2016; 4(6):504-505.

8. Schubart O, Diplopoda III. In South African Animal Life. 1966; 12:1-227.

9. Lawrence RF. The Spiroboloidea (Diplopoda) of the eastern half of southern Africa. Annals of the Natal Museum. 1967; 18:607-646.

10. Blanckenhorn WU, Dixon AFG, Fairbairn DJ, Foellmer MW, Gilbert P, Van der Linde K et al. Proximate Causes of Rensch's Rule: Does Sexual Size Dimorphism in Arthropods Result from Sex Differences in Development Time? The American Naturalist. 2007; 169(2):245-257.

11. Cooper MI. Sexual bimaturism in the millipede Centrobolus inscriptus (Attems). Journal of Entomology and Zoology Studies. 2016; 4(3):86-87.

12. Leutenegger W. Scaling of sexual dimorphism in body size and breeding system in primates. Nature. 1978; 272:610-611.

13. LaBarbera M. Analyzing Body Size as a Factor in Ecology and Evolution. Annual Review of Ecology and Systematics. 1989; 20:97-117.

14. Cooper MI. Sex ratios, mating frequencies and relative abundance of sympatric millipedes in the genus Centrobolus Cook. Arthropods 2014; 3(4):174-176.

15. Hochkirch A, Gröning J. Sexual size dimorphism in Orthoptera (sens. str.) - a review. Journal of Orthoptera Research. 2008; 17(2):189-196.

16. Hedrick AV, Temeles EJ. The evolution of sexual dimorphism in animals: Hypotheses and tests. Trends in Ecology and Evolution. 1989; 4(5):136-138.

17. Weissman DB, Judge KA, Williams SC, Whitman DW, Lee VF. Small-male mating advantage in a species of Jerusalem cricket (Orthoptera: Stenopelmatinae: Stenopelmatus). Journal of Orthoptera Research. 2008; 17(2):321-332.

18. Webb TJ, Freckleton RP. Only Half Right: Species with Female-Biased Sexual Size Dimorphism Consistently Break Rensch's Rule. PLoS ONE. 2007; 2(9):e897. 